\title{
Zika virus-associated Guillain-Barré syndrome: a warning for critical care physicians
}

\author{
Guillaume Thiery ${ }^{1,2^{*}}$, Ruddy Valentino ${ }^{3}$ and Hossein Meddhaoui ${ }^{3}$
}

(C) 2016 Springer-Verlag Berlin Heidelberg and ESICM

After yellow fever, dengue, West Nile and chikungunya, Zika virus opens a new chapter in the history of the threat from arbovirus.

Zika virus (ZIKV) belongs to the Flaviviridae family, genus Flavivirus. It was first identified in 1947 in rhesus monkeys in Uganda and isolated in humans in 1952. It is predominantly transmitted between human beings by Aedes mosquitos: Aedes aegypti is the main vector, but Aedes albopictus (the Asian tiger mosquito), a much more widely distributed mosquito in Southern Europe and the USA, might play a part too. Recent observations suggest that sexual transmission of the virus may be more common than previously thought [1]. In addition, the virus was detected in $3 \%$ of asymptomatic blood donors in French Polynesia, suggesting the possibility of a transmission by blood products [2].

In 2007 an outbreak occurred on the island of Yap, in the Federal State of Micronesia. An estimated $73 \%$ of the island's population were infected by the virus over a 3 -year period [3]. In 2013 a larger outbreak occurred in French Polynesia with an estimation of 32,000 infected patients between October 2013 and April 2014 [4]. In early 2015, the first case of ZIKV autochthonous transmission was identified in Brazil [5]. Since then the virus has spread across the Americas, affecting 31 countries in South America, Central America and the Caribbean $[6,7]$, and has become a global threat, according to the World Health Organization (WHO) [8]. The most recent affected territories are in the Caribbean, including Puerto Rico [7] and the French West Indies [9], particularly in Martinique where the incidence currently reaches 120

\footnotetext{
*Correspondence: guillaume.thiery.bih@gmail.com

${ }^{1}$ Intensive Care Unit, University Hospital of Pointe-à-Pitre/Abymes, Guadeloupe, France

Full author information is available at the end of the article
}

cases for 10,000 inhabitants and where an estimated $2.5 \%$ of the population has been infected [9].

Zika virus causes a mild illness after an incubation period of 3-12 days. Symptoms predominantly include fever, conjunctivitis, widespread maculopapular rash frequently pruritic, arthralgia and myalgia, but as many as $80 \%$ of infections may be asymptomatic $[2,3]$. The clinical presentation is close to that of dengue and chikungunya. During the acute phase, laboratory diagnosis is based on detection of ZIKV RNA by polymerase chain reaction (PCR) in blood, but the low viral load and the short duration of the viraemia, which rarely exceeds 5 days after the symptoms onset [10], limits the probability of a positive result. Detecting the virus in other body fluids, such as saliva, cerebrospinal fluid (CSF) or urine, might be a valuable alternative $[11,12]$. Urinary samples seem particularly interesting, as the virus can be detected at higher titers and for a longer period than in serum sample [13]. After the acute phase, serological diagnosis is compromised because of extensive cross-reactivity between antibodies triggered by different flavivirus infections or vaccination.

Serious neurological complications have led to the WHO declaring the Zika outbreak a global emergency [8]. Like with other flaviviruses, Zika has been found to trigger Guillain-Barré syndrome (GBS) during the outbreak in French Polynesia in 2013 [14]. In a recent case control study, the role of Zika virus in patients with GBS has been convincingly established during this epidemic [10]. In total, 42 cases of GBS were recorded, among whom $98 \%$ had antibodies against ZIKV and $100 \%$ had neutralizing antibodies against ZIKV. Thus, the risk of GBS was estimated at $0.24 / 1000$ ZIKV infections [10], compared to 0.25-0.65/1000 Campylobacter jejuni infections [15] and 0.6-2.2/1000 Cytomegalovirus infections [16]. Most patients $(88 \%)$ had a previous viral syndrome-associated rash (81\%), arthralgia (74\%),

\section{勿 Springer}


fever (58\%) and conjunctivitis (48\%), with a median time between viral syndrome and onset of neurological symptoms of 6 days (IQR 4-10). The progression of the neurological symptoms was rapid: the ascendant phase, from onset to peak, lasted a median of 6 days (IQR 4-9), and the plateau phase lasted a median of 4 days (IQR 3-10). The clinical picture comprised associated muscle weakness (86 \%), facial palsy (83 \%) and paraesthesia (83\%). The prevalence of swallowing troubles and respiratory disorders was 45 and $33 \%$, respectively. Electrophysiological findings were in favour of the acute motor axonal neuropathy (AMAN) type. Twelve $(29 \%)$ patients were mechanically ventilated. Importantly, they had a very long length of stay in the ICU of 51 days (IQR 16-70). Treatment did not differ from that of GBS from other origins: all patients were treated with intravenous immunoglobulin at a dosage of $2 \mathrm{~g} / \mathrm{kg}$ over $2-5$ days and one had plasmapheresis.

Confirmation of neurotropism of the virus has been reinforced by two recent observations. In Guadeloupe, French West Indies, an acute myelitis was diagnosed in a 15-year-old girl in whom high concentrations of the virus was found in blood, urine and CSF [17]. In Paris, France, an 81-year-old man was diagnosed with acute meningoencephalitis 10 days after he had returned from a 4-week stay in the South Pacific. ZIKIV was identified in the CSF by PCR and subsequently confirmed by virus growth on cellular culture [18].

These data obviously raise concerns for critical care physicians. First, given the high attack rate of ZIKV epidemics so far (73\% in Micronesia [3] and $66 \%$ in French Polynesia [10]), we must be prepared to face a high number of patients with GBS in areas in which the ZIKIV is circulating. With 42 out of 268,270 inhabitants diagnosed with definite ZIKV-induced GBS, the extrapolation to a larger population is definitely concerning, especially as the outbreak is still spreading dramatically. In Martinique and Guadeloupe (French West Indies), six patients have been hospitalised in ICUs with GBS since 1 January 2016, among whom two had a confirmed ZIKV infection [12], whereas the rate is usually around 10 cases per year [12]. Secondly, although the ascendant phase and the plateau are relatively short in the global population, the duration of respiratory muscle weakness might be very long in some patients requiring mechanical ventilation, leading to notably longer duration of stay in the ICU. The combination of these two factors may lead to overwhelming pressure on ICUs. As an example, the French West Indies preparedness plan has expected 160 GBS cases including 40 requiring ICU admission for a global population of 800,000 inhabitants. Both critical care physicians and health policy decision makers should take this threat seriously into account in allocating appropriate resources in areas affected by the epidemic.

\section{Author details}

${ }^{1}$ Intensive Care Unit, University Hospital of Pointe-à-Pitre/Abymes, Guadeloupe, France. ${ }^{2}$ University of French West Indies/Université des Antilles, Guadeloupe, France. ${ }^{3}$ Intensive Care Unit, University Hospital of Fort de France, Martinique, France.

Received: 4 April 2016 Accepted: 16 April 2016

Published online: 27 April 2016

References

1. McCarthy M (2016) US health officials investigate sexually transmitted Zika virus infections. BMJ 352:i1180

2. Musso D, Nhan T, Robin E et al (2014) Potential for Zika virus transmission through blood transfusion demonstrated during an outbreak in French Polynesia, November 2013 to February 2014. Euro Surveill 19:14

3. Duffy MR, Chen T-H, Hancock WT et al (2009) Zika virus outbreak on Yap Island, Federated States of Micronesia. N Engl J Med 360:2536-2543

4. Mallet H-P, Vial AL, Musso D (2015) Bilan de l'épidémie à virus Zika en Polynésie Française, 2013-2014. http://www.hygiene-publique.gov.pf/ IMG/pdf. Accessed 14 Mar 2016

5. Zanluca C, de Melo VCA, Mosimann ALP et al (2015) First report of autochthonous transmission of Zika virus in Brazil. Mem Inst Oswaldo Cruz 110:569-572

6. Hennessey M, Fischer M, Staples JE (2016) Zika virus spreads to new areas-region of the Americas, May 2015-January 2016. MMWR Morb Mortal Wkly Rep 65:55-58

7. Thomas DL, Sharp TM, Torres J et al (2016) Local transmission of Zika virus-Puerto Rico, November 23, 2015-January 28, 2016. MMWR Morb Mortal Wkly Rep 65:154-158

8. WHO (2016) WHO Director-General summarizes the outcome of the Emergency Committee regarding clusters of microcephaly and Guillain-Barré syndrome. http://www.who.int/mediacentre/news/statements/2016/emergency-committee-zika-microcephaly/en/. Accessed 14 Mar 2016

9. Emergence du virus Zika aux Antilles Guyane Situation épidémiologique. Point épidémiologique du 3 mars 2016. http://www.invs.sante.fr/fr/content/download/123427/437191/version/102/file/pe_zika_antilles_guyane_040316.pdf. Accessed 14 Mar 2016

10. Cao-Lormeau VM, Blake A, Mons S (2016) Guillain-Barré syndrome outbreak associated with Zika virus infection in French Polynesia: a casecontrol study. Lancet 387:1531-1539

11. Charrel RN, Leparc Goffart I, Pas S et al (2016) State of knowledge on Zika virus for an adequate laboratory response. http://www.who.int/bulletin/ online_first/zika_open/en/. Accessed 14 Mar 2016

12. Roze B, Najouillah F, Fergé J et al (2016) Zika virus detection in urine from patients with Guillain-Barré syndrome on Martinique, January 2016. Euro Surveill 21:9

13. Gourinat A-C, O'Connor O, Calvez E et al (2015) Detection of Zika virus in urine. Emerg Infect Dis 21:84-86

14. Oehler E, Watrin L, Larre P et al (2014) Zika virus infection complicated by Guillain-Barre syndrome_case report, French Polynesia, December 2013. Euro Surveill 19:pii:20720

15. Yuki N, Hartung H-P (2012) Guillain-Barré syndrome. N Engl J Med 366:2294-2304

16. Orlikowski D, Porcher R, Sivadon-Tardy V et al (2011) Guillain-Barre syndrome following primary cytomegalovirus infection: a prospective cohort study. Clin Infect Dis 52:837-844

17. Mécharles S, Herrmann C, Poullain P et al (2016) Acute myelitis due to Zika virus infection. Lancet 387:1481

18. Carteaux G, Maquart M, Bedet A et al (2016) Zika virus associated with meningoencephalitis. N Engl J Med. doi:10.1056/NEJMc1602964 